\title{
The Evaluation of Blood Donor Deferral Causes: A Tertiary Care Centre- based Study
}

\author{
Suhailur Rehman ${ }^{1 *}$, Sayeedul Hasan Arif', Ghazala Mehdi ${ }^{2}$, Sadaf Mirza', Noora Saeed ${ }^{1}$ and Faraz Yusuf ${ }^{3}$ \\ IJ N Medical College, Aligarh Muslim University, Aligarh, India \\ ${ }^{2}$ Department of Pathology, J N Medical College, Aligarh Muslim University, Aligarh, India \\ ${ }^{3}$ Department of Ophthalmology, J N Medical College, Aligarh Muslim University, Aligarh, India
}

\begin{abstract}
Blood safety is a major issue all over the world in transfusion medicine. For this, donor selection is necessary in addition to the screenings of blood bags for infectious diseases. Deferrals lead to loss of precious blood/ components available for transfusion. For preventing this, we should be having knowledge of causes of deferral and their frequency. In this study, causes of donor deferral were evaluated retrospectively from January 2007 to December 2011 in the blood bank of Jawaharlal Nehru Medical College (JNMC), Aligarh Muslim University (AMU), ALIGARH (India). Analysis of the deferrals showed that temporary deferral was more common than permanent deferral. Most common cause in permanent deferral was HBsAg positivity. Causes among temporary deferral were anemia $(\mathrm{Hb}<12.5 \mathrm{gm} \%)$, malaria in last 3 months, jaundice, alcohol intake in last 3 days, weight $<45 \mathrm{~kg}$, age $<18 \mathrm{yrs}$, patients on antibiotic, previous donation in last 3 month, typhoid in last 1 year, dog bite etc.
\end{abstract}

Keywords: Blood donor; Deferral; Blood safety

\section{Introduction}

In current medical and surgical practice, a blood transfusion can be a vital, life-saving procedure. But it requires an adequate supply of safe blood from a healthy donor. For this, donor selection is necessary in addition to the screenings of blood bags for infectious diseases. However deferrals lead to loss of precious blood/components available for transfusion. For preventing this we should be having knowledge of causes of deferral and their frequency. The National AIDS Control Organization's (NACO) statistics show that the annual rate of blood donation in India is about 7.4 million units, against the requirement of 10 million units [1]. According to World Health Organization (WHO) figures, over 81 million units of blood are collected annually worldwide but only $39 \%$ are collected in developing countries which have $82 \%$ of the world's population [2]. A blood bank plays an important role in ensuring the supply of safe blood as and when required. While it is important to ensure that there is an adequate supply of blood, it is also essential that the blood collection process does not harm either the donor or the recipient. This is achieved by having donor deferral criteria [3] and stringent screening of collected blood for possible Transfusion Transmissible Infections (TTIs) [4]. Deferrals are divided into permanent and temporary. Few studies done in India in the past have provided different common reasons for deferral of whole blood donors, highlighting differing demographic profile in different parts of the country $[5,6]$. The aim of our study is to know the profile of the blood donors and causes of the permanent and temporary deferral and their frequency. This retrospective study was conducted in the blood bank of JNMC, AMU, Aligarh (India) from January 2007 to December 2011.

\section{Materials and Methods}

This retrospective study included all the donors reporting for blood donation in the blood bank of JNMC, AMU, Aligarh (India) from $1^{\text {st }}$ January 2007 to $31^{\text {st }}$ December 2011. The donors were evaluated on the basis of clinical history, physical examination, $\mathrm{Hb}$ estimation, blood pressure, and temperature. NACO guidelines were used for deferral of blood donors. Data was collected from the records maintained by the blood bank. Hemoglobin was measured by Haemometer Sahli plano paralal (Toptech biomedicals, Thane, India). Blood samples of these donors were screened for HBsAg by Microscreen HBsAg ELISA Test kit (NACO supplies, Third National HIV/AIDS Control Project, Span diagnostics limited, India) and anti HCV by SD HCV ELISA 3.0 the $3^{\text {rd }}$ Generation Anti-HCV ELISA test (NACO supplies, Third National HIV/AIDS Control Project, SD Bio standard diagnostics private limited, India), anti-HIV by SD HIV1/2 ELISA 3.0 the $3^{\text {rd }}$ generation Anti HIV1/2 ELISA test (NACO supplies, Third National HIV/AIDS Control Project, SD Bio Standard Diagnostics Private limited, India), Malaria by SD Malaria Ag Pf/Pan (SD Bio Standard Diagnostics Private Limited, Gurgaon, Haryana, India) and syphilis by CARBOGEN, RPR card test (Tulip diagnostics private limited, India) from 2007 to 2010 and in 2011 by SD BIOLINE syphilis (Bio standard diagnostics private limited, Gurgaon, Haryana, India) a solid phase immunochromatographic assay for the qualitative detection of antibodies of all isotypes (IgG, IgM, IgA) against Treponema pallidum antigen.

\section{Result}

Out of 53,950 people who had come for blood donation, 51,266 were males (95\%) and 2,684 were females (5\%) (Table 1). 6,690 donors (12.4\%) deferred out of which 4,262 (63.7\%) were temporary and 2,428 (36.3\%) were permanent (Table 2). Overall males $(6,142 ; 11.38 \%)$ were deferred more than the females $(548 ; 1.02 \%)$ but females $(548 ; 20.41 \%)$ were found to have higher deferral rate among the female donors than males $(6,142 ; 11.98 \%)$ (Table 3$)$. Analysis of the deferrals showed that the temporary deferral was more common than permanent deferral.

*Corresponding author: Suhailur Rehman, Resident, J N Medical College Aligarh Muslim University, Aligarh, India, E-mail: suhailurrehman2k2@gmail.com

Received July 17, 2012; Accepted October 01, 2012; Published October 03, 2012

Citation: Rehman S, Arif SH, Mehdi G, Mirza S, Saeed N, et al. (2012) The Evaluation of Blood Donor Deferral Causes: A Tertiary Care Centre-based Study. J Blood Disorders Transf 3:131. doi:10.4172/2155-9864.1000131

Copyright: (c) 2012 Rehman S, et al. This is an open-access article distributed under the terms of the Creative Commons Attribution License, which permits unrestricted use, distribution, and reproduction in any medium, provided the original author and source are credited. 


\begin{tabular}{|c|c|c|c|}
\hline & No. of registrations & No. of deferrals & \% deferrals of total registration \\
\hline Male & 51266 & 6142 & $11.38 \%$ \\
\hline Female & 2684 & 548 & $1.02 \%$ \\
\hline Total & 53950 & 6690 & $12.40 \%$ \\
\hline
\end{tabular}

Table 1: Demographic profile of the donors.

\begin{tabular}{|c|c|c|c|}
\hline & No. of deferrals & $\%$ of total deferrals & $\%$ deferrals of total registration \\
\hline Temporary & 4262 & $63.7 \%$ & $7.90 \%$ \\
\hline Permanent & 2428 & $36.3 \%$ & $4.50 \%$ \\
\hline $\begin{array}{c}\text { Total no. of } \\
\text { deferrals }\end{array}$ & $\begin{array}{c}6690(12.4 \% \text { of } \\
\text { total registration) }\end{array}$ & $100 \%$ & $12.40 \%$ \\
\hline
\end{tabular}

Table 2: Frequency of permanent and temporary deferrals.

\begin{tabular}{|c|c|c|c|}
\hline Male & 51266 & 6142 & $\begin{array}{c}\% \text { of deferrals among male/female } \\
\text { donors }\end{array}$ \\
\hline Female & 2684 & 548 & $11.98 \%$ \\
\hline
\end{tabular}

Table 3: Frequency of deferrals among male and female donors.

Most common cause among temporary deferral was anemia $(\mathrm{Hb}$ $<12.5 \%$ ), followed by malaria in last 3 months (Table 4 ). Most common cause in permanent deferral was HBsAg positivity followed by age $>60$ yrs (Table 5).

\section{Discussion}

Donor selection has vital importance in blood banking and transfusion medicine. The preamble of our study was to device a protocol which could prevent the loss of whole blood/component and be safe for the donors and recipients.

Most of the donors were males (95\%); women accounted for only $5 \%$ of the donors. Present study showed that female donors $(20.41 \%)$ were deferred more frequently than male donors (11.98\%) which might be due to wide prevalence of anemia in female donors.

Donor deferral (12.40\%) in the study was very much similar to various American, European and Asian studies. Zou et al. [6] reported a deferral rate of $12.8 \%$ in their 6 years study of American Red Cross blood service and Custer et al. [7] showed a deferral rate of $13.6 \%$. In a European study conducted by Lawson-Ayayi and Salmi [8], 10.8\% of donors were deferred. Arslan [9] reported a donor deferral rate of $14.6 \%$ in Turkish donors. Lim et al. [10] reported a deferral rate of 14.4\% in Singapore (Asia) and Bahadur et al. [4] reported 9\% in Delhi (India). Rabeya et al. [11] found a very low deferral rate in their study (5.6\%) which could be due to different donor selection criteria.

The most common cause among temporary deferral was anemia (17.95\%) as compared to Halperin et al. [12] which showed low hemoglobin as the most common cause in $46 \%$ of the temporary deferral. The study done by Arslan [9] in Turkish donors showed low hemoglobin as the most common cause of deferral in $20.7 \%$ of overall deferral. The findings in our study were very much similar to these studies. Malaria accounted for second most common cause of temporary deferral which might be due to the fact that Aligarh city and its surroundings from where most of the donors received were in endemic zone. This finding is not reported in any of the previous studies, due to the fact that most of the studies were conducted in non endemic zones of malaria. The incidence of malaria can be decreased if the breeding of mosquito is controlled by organizing educational programs regarding the control of mosquito breeding as well as by upgrading the malaria control programs in these endemic zones by the government. Anemia can be cured if proper treatment of these donors

\begin{tabular}{|c|c|c|c|}
\hline Causes & Number & $\begin{array}{c}\% \text { Temporary } \\
\text { deferrals }\end{array}$ & $\begin{array}{l}\text { \% Total } \\
\text { deferrals }\end{array}$ \\
\hline Anemia, $\mathrm{Hb}<12.5 \%$ & 765 & $17.95 \%$ & $11.43 \%$ \\
\hline Malaria in last 3 month & 505 & $11.85 \%$ & $7.54 \%$ \\
\hline Weight $<45 \mathrm{~kg}$ & 454 & $10.65 \%$ & $6.79 \%$ \\
\hline Jaundice last 1 year & 390 & $9.15 \%$ & $5.83 \%$ \\
\hline Alcohol in last $72 \mathrm{hrs}$ & 380 & $8.92 \%$ & $5.68 \%$ \\
\hline On antibiotic/ aspirin for last 3 days & 279 & $6.55 \%$ & $4.17 \%$ \\
\hline Upper respiratory tract infection & 251 & $5.90 \%$ & $3.75 \%$ \\
\hline Age $<18$ years & 200 & $4.70 \%$ & $3.00 \%$ \\
\hline Previous donation in last 3 months & 171 & $4.01 \%$ & $2.56 \%$ \\
\hline Syphilis for 1 month & 164 & $3.85 \%$ & $2.45 \%$ \\
\hline Hypertension & 140 & $3.29 \%$ & $2.09 \%$ \\
\hline Typhoid in last 1 year & 128 & $3.00 \%$ & $1.91 \%$ \\
\hline $\begin{array}{l}\text { Dental extraction/surgery in last } 6 \\
\text { month }\end{array}$ & 120 & $2.80 \%$ & $1.80 \%$ \\
\hline Diabetes on insulin & 110 & $2.58 \%$ & $1.64 \%$ \\
\hline pregnant/lactating female & 90 & $2.10 \%$ & $1.35 \%$ \\
\hline $\begin{array}{l}\mathrm{H} / \mathrm{O} \text { Tuberculosis with no ATT intake/ } \\
\text { incomplete treatment. }\end{array}$ & 51 & $1.20 \%$ & $0.76 \%$ \\
\hline $\begin{array}{l}\text { Dog or cat bite/rabies vaccination in } \\
\text { last } 1 \text { year }\end{array}$ & 43 & $1.00 \%$ & $0.64 \%$ \\
\hline Poor vein & 9 & $0.20 \%$ & $0.13 \%$ \\
\hline Stroke & 4 & $0.10 \%$ & $0.06 \%$ \\
\hline Tattoo /ear piercing in last 1 year & 4 & $0.10 \%$ & $0.06 \%$ \\
\hline \multirow[t]{2}{*}{ Bhang addiction } & 4 & $0.10 \%$ & $0.06 \%$ \\
\hline & 4262 & $100 \%$ & $63.70 \%$ \\
\hline
\end{tabular}

Table 4: Causes of temporary deferrals with their relative proportions.

\begin{tabular}{|l|c|c|c|}
\hline \multicolumn{1}{|c|}{ Causes } & Number & $\begin{array}{c}\text { \% Permanent } \\
\text { deferrals }\end{array}$ & $\begin{array}{c}\% \text { Total } \\
\text { deferrals }\end{array}$ \\
\hline HBV positive & 1571 & $64.70 \%$ & $23.48 \%$ \\
\hline Age $>60$ years & 276 & $11.37 \%$ & $4.13 \%$ \\
\hline HCV positive & 169 & $6.96 \%$ & $2.53 \%$ \\
\hline $\begin{array}{l}\text { Chronic obstructive lung } \\
\text { disease }\end{array}$ & 110 & $4.53 \%$ & $1.64 \%$ \\
\hline HIV-1,2 positive & 96 & $3.95 \%$ & $1.43 \%$ \\
\hline Heart disease & 90 & $3.71 \%$ & $1.35 \%$ \\
\hline Asthma & 70 & $2.88 \%$ & $1.05 \%$ \\
\hline Epilepsy & 30 & $1.24 \%$ & $0.45 \%$ \\
\hline $\begin{array}{l}\text { leukemia/lymphoma/multiple } \\
\text { myeloma }\end{array}$ & 10 & $0.41 \%$ & $0.15 \%$ \\
\hline $\begin{array}{l}\text { patient who received } \\
\text { chemotherapy }\end{array}$ & 6 & $0.25 \%$ & $0.09 \%$ \\
\hline & 2428 & $100 \%$ & $36.3 \%$ \\
\hline
\end{tabular}

Table 5: Causes of permanent deferrals with their relative proportions.

is undertaken with follow up. The other causes of temporary deferral included low body weight, upper respiratory infection, syphilis, jaundice and others which are easily curable. A proper track for follow up of temporarily deferred donors regarding their management should be made in the blood bank so that these donors can be recruited back in donors' pool.

In our study $36.3 \%$ of donors were deferred for permanent reasons. Our findings (36.3\%) were much higher than Custer et al. [7] who reported a permanent deferral rate of $10.6 \%$ and Arslan [9] who reported a rate of $10 \%$. This high frequency was due to the inclusion of transfusion transmissible infection in our study especially Hepatitis $\mathrm{B}$ infection (HBV) which was not studied thoroughly in the above mentioned publications. Present study showed HBsAg positive as the most common cause of permanent deferral as compared to Bahadur 
et al. [4] who showed Hypertension as the most common cause. The method used for Hepatitis B testing as mentioned in material and method detect HBsAg positivity, indicates that either the donor had a subclinical disease/acute or chronic viral infection/false positive cases. So for the benefit of the patients these donors were deferred permanently. This is very important finding which should be of great concern as Hepatitis B infection is increasing more among the local population and knowledge of routes of transmission of TTI can decrease the seroprevalence of Hepatitis B infection, further this infection can be controlled by vaccination which should be encouraged. Public awareness programs relating to routes of transmission for these infections should be encouraged.

\section{Conclusion}

The present study showed that although donor deferral rates were very much similar in different populations, the reasons for deferral differ, reflecting difference in socioeconomic status and environment. However, some studies showed different deferral rate which could be due to different donor selection criteria. Analysis of deferral patterns may help medical personnel and doctors to be more focused in donor screening especially of those who are having higher frequency e.g., Anemia, Malaria and Hepatitis B infection. Temporary deferred donors require proper follow up and management so as not to lead to a diminished supply of future donors. Government establishment need proper attention to control malaria. For this prevention of mosquito from breeding is needed. Hepatitis B infection can be prevented by educating people regarding the importance of Hepatitis B vaccination and routes of transmission. Finally, the approach to improve safety of blood and blood products and to decrease loss of precious blood/ component must include four steps: (1) detail history based on NACO/ WHO guidelines, (2) physical examination, (3) laboratory tests including ELISA for anti HIV, anti HCV and HBsAg and other test for malaria and syphilis and (4) public awareness programmes.

So to conclude, it is important to determine the rate and causes of blood donor deferral for the safety of blood/component transfusion and also to guide the recruitment efforts to prevent loss of precious blood/components at local, national and international levels.

\section{References}

1. Department of AIDS Control Ministry of Health and Family Welfare Government of India Annual report 2008- 2009: 27.

2. Baxi A (2008) Misconceptions over blood donation causing shortage in India.

3. Newman B (2001) Blood donor suitability and allogeneic whole blood donation. Transfus Med Rev 15: 234-244.

4. Bahadur S, Jain S, Goel RK, Pahuja S, Jain M (2009) Analysis of blood donor deferral characteristics in Delhi, India. Southeast Asian J Trop Med Public Health 40: 1087-1091.

5. Chaudhary RK, Gupta D, Gupta RK (1995) Analysis of donor-deferral pattern in a voluntary blood donor population. Transfus Med 5: 209-212.

6. Zou S, Musavi F, Notari EP, Rios JA, Trouern-Trend J, et al. (2008) Donor deferral and resulting donor loss at the American Red Cross Blood Services, 2001 through 2006. Transfusion 48: 2531-2539.

7. Custer B, Johnson ES, Sullivan SD, Hazlet TK, Ramsey SD, et al. (2004) Quantifying losses to the donated blood supply due to donor deferral and miscollection. Transfusion 44: 1417-1426.

8. Lawson-Ayayi S, Salmi LR (1999) Epidemiology of blood collection in France. Eur J Epidemiol 15: 285-292.

9. Arslan $O$ (2007) Whole blood donor deferral rate and characteristics of the Turkish population. Transfus Med 17: 379-383.

10. Lim JC, Tien SL, Ong YW (1993) Main causes of pre-donation deferral of prospective blood donors in the Singapore Blood Transfusion Service. Ann Acad Med Singapore 22: 326-331.

11. Rabeya Y, Rapiaah M, Rosline H, Ahmed SA, Zaidah WA, et al. (2008) Blood pre-donation deferrals--a teaching hospital experience. Southeast Asian J Trop Med Public Health 39: 571-574.

12. Halperin D, Baetens J, Newman B (1998) The effect of short-term, temporary deferral on future blood donation. Transfusion 38: 181-183.

13. Choudhury LP, Tetali S (2008) Notification of transfusion transmitted infection. Indian J Med Ethics 5: 58-60. 